\title{
CALCIUM OXIDE FROM Pomacea canaliculata AND Babylonia spirata SNAILS
}

\author{
Triayu Septiani ${ }^{1 *}$, Nurlisa Hidayati ${ }^{1}$, Risfidian Mohadi ${ }^{1}$ \\ ${ }^{1}$ Department of Chemistry, Faculty of Mathematic and Natural Sciences, Sriwijaya University \\ Corresponding AuthorEmail: triayuseptiani@gmail.com
}

\begin{abstract}
The preparation of $\mathrm{CaO}$ from golden snail (Pomacea canaliculata) and lion snail (Babylonia spirata) through decomposition at various temperature i.e $700^{\circ}, 800^{\circ}, 900^{\circ}$ and $1000^{\circ} \mathrm{C}$ during 3 hours has been carried out. Calcium oxide from decomposition were characterized using X-Ray difractometer. Furthermore, the characterization was continued using FT-IR spectrophotometer and determination of surface area using BET analysis. The results showed that the optimum temperature for preparation of $\mathrm{CaO}$ from golden snail and lion snail at $900^{\circ} \mathrm{C}$ with $2 \theta$ values are: $32.2^{\circ}, 37.4^{\circ}, 54^{\circ}, 64.2^{\circ}, 67.3^{\circ}$ and $32.4^{\circ}, 37.5^{\circ}, 67.5^{\circ}$, respectively. FT-IR spectra showed characteristic vibrations for the $\mathrm{Ca}-\mathrm{O}$ in the sample golden snail and lion snail combustion products at a temperature of $900^{\circ} \mathrm{C}$. Ca-O absorption of golden snail samples in the wavenumber around $362.62 \mathrm{~cm}^{-1}$ and lion snail seen in wavenumber around $384.76 \mathrm{~cm}^{-1}$ indicating the presence of $\mathrm{Ca}-\mathrm{O}$ vibration of the metal oxide of preparation. Golden snail and the lion snail combustion at $900{ }^{\circ} \mathrm{C}$ temperature of each sample which has a surface area of $20.495 \mathrm{~m}^{2} / \mathrm{g}$, while the lion snail $17.308 \mathrm{~m}^{2} / \mathrm{g}$. Pore diameter of golden snail $3.753 \mathrm{~nm}$ and $11.319 \mathrm{~nm}$ of lion snail. All $\mathrm{CaO}$ can be categorized as mesoporous material.
\end{abstract}

Keywords: golden snail, lion snail, decomposition, $\mathrm{CaO}$

\section{INTRODUCTION}

The development of acid base catalyst is still carried out until this decade due to application for industrial applications. Research of development acid catalyst is sharply increased compared with basic catalyst due to easy synthetic way. The basic catalyst is important for preparation of biodiesel, which has renewable energy in the future. Conventional basic catalyst such as sodium hydroxide, potassium hydroxide (group 1) or calcium oxide, barium oxide, and strontium oxide (group 2) is commercially available (Elkins et.al, 2016). These catalysts are toxic and high price. Thus the research to obtain economic and non-toxic basic catalyst is vital.

Calcium oxide is one of the basic catalyst commonly used for production of biodiesel from vegetable oils (Wei et.al, 2009). Calcium oxide is strong base and effective as catalyst for biodiesel production and conversion of natural sources to chemical bio-based products. Commercial calcium oxide is produced from limestone by industrial process then the price is still expensive. In order to obtain calcium oxide with cheaper source, decomposition of calcium carbonate from natural sources is interesting. Calcium carbonate can be obtained from various mollusk shells such as snails shell and decapoda shells such as crab shell. Decomposition of calcium carbonate will produce calcium oxide as main product and calcium hydroxide as by-product. The successfully decomposition process is depending on temperature decomposition (Chakraborty and Banerjee, 2011).

Various sources of calcium carbonate from mollusk or decapoda have been used to produce calcium oxide such as Mollusk (Pila globosa) (Agrawal et.al, 2012), several shells (Viriya-Empikul et.al,

\footnotetext{
Article History

Received: 14 January 2017

Received in revised form: 21 April 2017

Accepted: 30 April 2017
}

DOI: 10.26554/sti.2017.2.3.68-70

(C)2017 Published under the term of the CC BY NC SA license
2010), oyster shell (Nakatani e.al, 2009), crab (Scylla serrata) shell (Boey et.al, 2009) and also fish bone (Lesbani et.al, 2016). All calcium oxide from these preparation was successfully applied as catalyst for biodiesel production.

In this research, golden snail (Pomacea canaliculata) and lion snail (Babylonia spirata) from local source in Bengkulu, Indonesia were decomposed at various temperatures to obtain calcium oxide. Calcium oxide from decomposition process was characterized using XRD powder analysis, FTIR spectroscopy analysis, and surface area analysis using nitrogen sorption desorption.

\section{EXPERIMENTAL SECTION}

\section{Chemicals and Instrumentations}

Methanol was supplied from Merck and used directly after purchased. Water was supplied from Department of Chemistry, Sriwijaya University by pore ion exchange filtration method. Golden snail and lion snail were obtained from "Pantai Panjang" in Bengkulu area.

FTIR spectrum was recorded using Shimadzu Prestige-21 FTIR spectrophotometer by $\mathrm{KBr}$ method. Spectrum was scanned from wavenumber $300-4000 \mathrm{~cm}^{-1}$. XRD powder patterns were obtained from Shimadzu LabX-6000 diffractometer and sample was scanned at $1^{\circ} \mathrm{min}^{-1}$. Surface area analysis was performed using Autosorb iQ automated gas sorption analyzer Quantachrome.

\section{Preparation of Calcium Oxide}

Golden snail and lion snail was washed with water. Shell of golden snail and lion snail was dried at $110^{\circ} \mathrm{C}$ overnight. Shell was crushed and sieve 100 mesh. Material was washed with methanol for 24 hours following with drying at $100^{\circ} \mathrm{C}$ overnight. Sample was decomposed using furnace under oxygen atmospheric condition for 3 hours. Temperature was adjusted at 700, 800, 900, and 1000 ${ }^{\circ} \mathrm{C}$. Sample was dried at $80{ }^{\circ} \mathrm{C}$ in oven and kept in desiccator under silica gel. Material was then characterized using XRD powder, FTIR, and surface area analyses. 


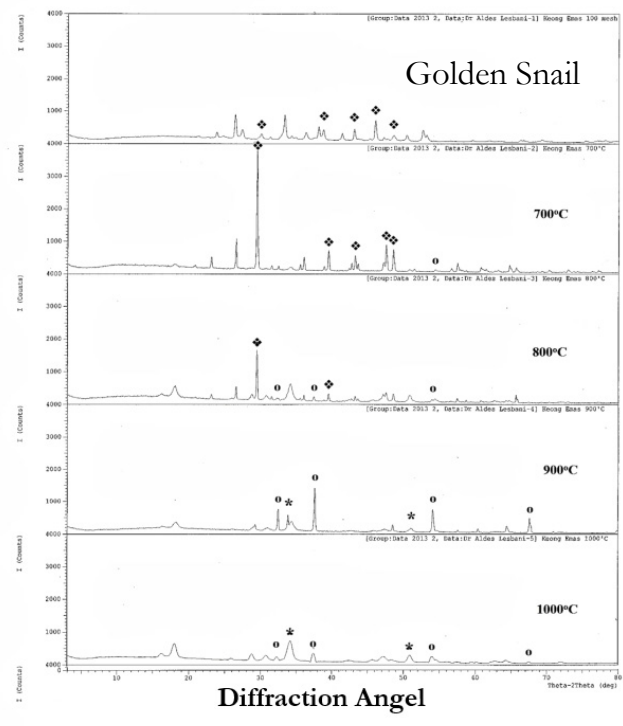

Figure 1. XRD powder patterns of decomposition of golden snail shell at various temperatures.

\section{RESULTS AND DISCUSSION}

Shell of golden snail and lion snail contains calcium carbonate. Calcium carbonate is basic natural compound. Decomposition was conducted in order to convert calcium carbonate to calcium oxide. On the other hand, decomposition is also to remove organic substances on shells. Transformation of calcium carbonate to calcium oxide was occurred at $700-800{ }^{\circ} \mathrm{C}$. Thus this experiment using temperature range $700-1000{ }^{\circ} \mathrm{C}$ for decomposition of golden snail and lion snail.

The results of decomposition of golden snail and lion snail showed that various weight of products were obtained. Products were obtained in the range $22-45 \%(\mathrm{w} / \mathrm{w})$ and did not depending on temperature. All products after decomposition were obtained in white bulky powder, thus analysis using XRD powder analysis was conducted for the first as shown in Figure 1 for golden snail and Figure 2 for lion snail.

To know the optimum temperature decomposition of golden snail and lion snail shells, XRD powder patterns in Figure 1 and 2 should be compared with XRD calcium oxide standard and also calcium carbonate and calcium hydroxide standard. All standard was obtained from Joint Committee on Powder Diffraction Standard (JCPDS). The JCPDS data for calcium carbonate, calcium oxide, and calcium hydroxide is presented in Table 1.

Figures 1 and 2 showed that temperature decomposition at 900 ${ }^{\circ} \mathrm{C}$ give diffraction similar calcium oxide standard from JCPDS data. Other decomposition temperatures did not give any significant with calcium oxide standard as shown in Table 1. Temperature decomposition at $1000{ }^{\circ} \mathrm{C}$ has diffraction of calcium hydroxide (Lesbani et.al, 2013). This phenomenon is due to hot material calcium oxide at high temperature will absorb water from air. Temperature below $900{ }^{\circ} \mathrm{C}$ is not enough to convert calcium carbonate to calcium oxide, then small diffraction of calcium carbonate was still remained. Thus further characterization using FTIR spectroscopy will measure material after decomposition at $900{ }^{\circ} \mathrm{C}$ for both golden snail and lion snail.

FTIR spectrum of calcium oxide from decomposition of golden snail and lion snail at $900{ }^{\circ} \mathrm{C}$ is shown in Figure 3. The IR spec-

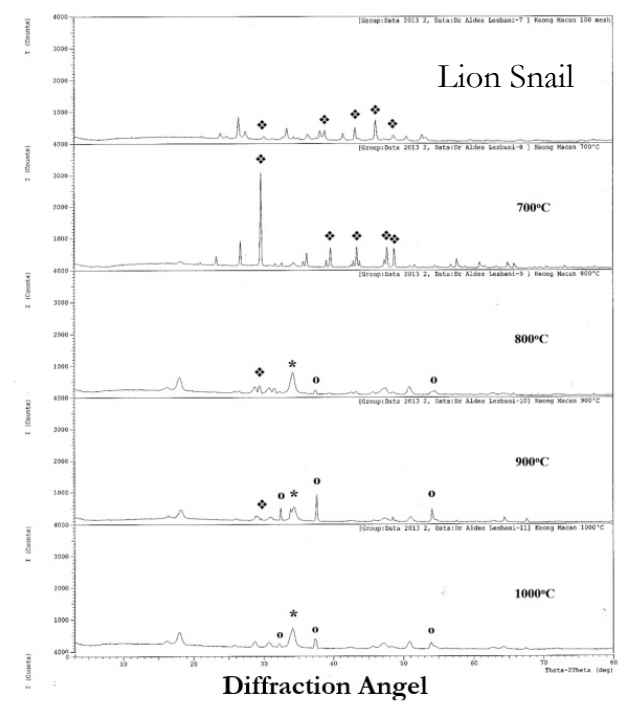

Figure 2. XRD powder patterns of decomposition of lion snail shell at various temperatures.

trum is compared with IR spectrum of calcium oxide standard. If the vibration of decomposed material is similar with standard, then decomposition of golden snail and lion snail shell is successfully conducted. FTIR spectrum of golden snail and lion snail is almost similar. Vibration of $\mathrm{Ca}-\mathrm{O}$ of lion snail was appeared at wavenumber $362.6 \mathrm{~cm}^{-1}$ while golden snail at $384.8 \mathrm{~cm}^{-1}$. Stretching vibration of O-C-O from carbonate was also appeared in both golden snail and lion snail. That vibration was appeared at wavenumber 1419.6 $\mathrm{cm}^{-1}$. In the other sides, bending vibration of $\mathrm{C}-\mathrm{O}$ was appeared at wavenumber $870 \mathrm{~cm}^{-1}$. Vibration at around wavenumber $860 \mathrm{~cm}^{-1}$ is typical for calcium carbonate (Tang et.al, 2013). Although decomposed material has small peak vibration of calcium carbonate but according to XRD powder patterns in Figure 1 and 2, we can conclude that decomposition of golden snail and lion snail shells is successfully conducted at $900{ }^{\circ} \mathrm{C}$ and physical properties of decomposed material similar with calcium oxide standard.

Further characterization of decomposed material was conducted using surface area analysis by nitrogen sorption desorption. The results of surface area analysis toward golden snail and lion snail decomposed at $900{ }^{\circ} \mathrm{C}$ are presented in Table 2 .

Data in Table 2 showed that decomposed material from golden snail and lion snail shells was classified as mesoporous material. According to IUPAC, mesoporous materials are materials with pore diameter 2-50 $\mathrm{nm}$. Other classes are microporous and macroporous with pore diameter less than $2 \mathrm{~nm}$ and more than $50 \mathrm{~nm}$, respectively. Pore distribution for golden snail and lion snail shell decomposed at $900{ }^{\circ} \mathrm{C}$ is presented in Figure 4 and 5, respectively.

Table 1. Diffraction standard of $\mathrm{CaO}, \mathrm{CaCO} 3$, and $\mathrm{Ca}(\mathrm{OH}) 2$ from JCPDS file data.

\begin{tabular}{lccccc}
\hline \multicolumn{1}{c}{ Compound } & \multicolumn{5}{c}{ Diffraction $2 \theta(\mathrm{deg})$} \\
\hline Calcium oxide & 32.2 & 37.3 & 53.8 & 64.1 & 67.3 \\
Calcium carbonate & 29.4 & 39.4 & 43.2 & 47.4 & 48.5 \\
Calcium hydroxide & 28.6 & 34.1 & 47.1 & 50.8 \\
\hline
\end{tabular}




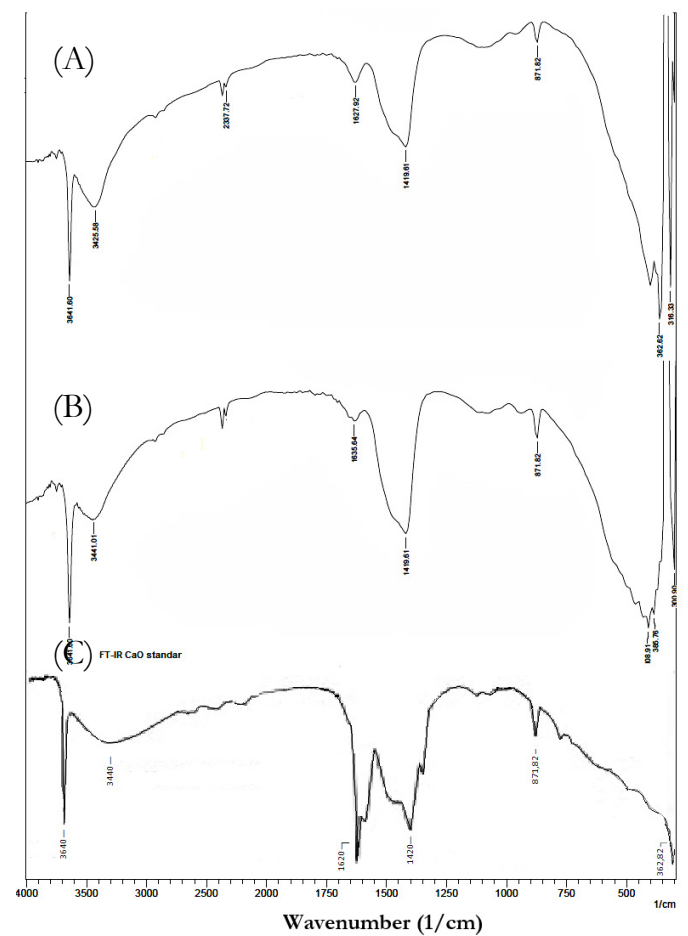

Figure 3. FTIR spectrum of calcium oxide standard (C) and decomposed from golden snail (B) and lion snail shells (A).

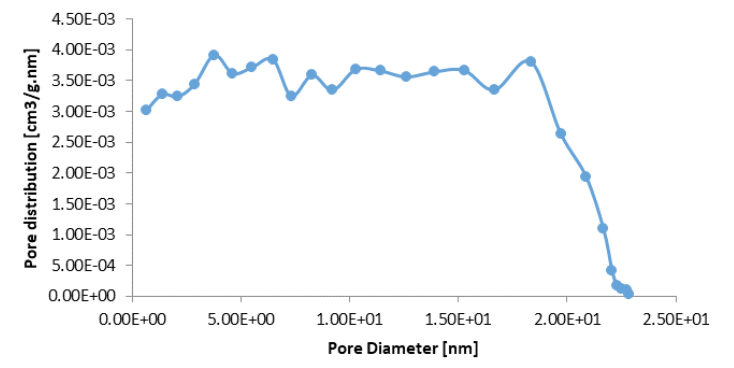

Figure 4. Distribution of pore diameter for golden snail after decomposition at $900 \mathrm{oC}$.

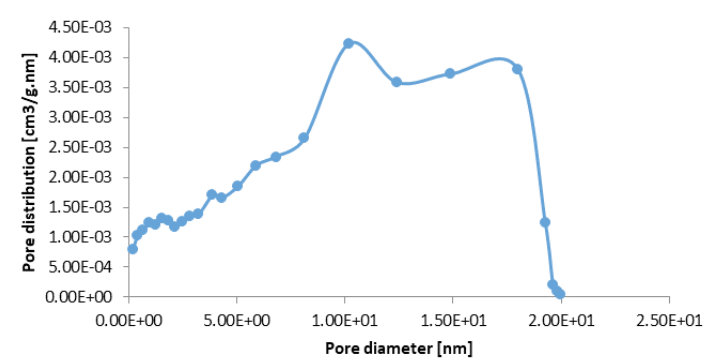

Figure 5. Distribution of pore diameter for lion snail after decomposition at 900 oC.

Table 2. Surface area analysis of decomposed golden snail and lion snail shells at $900^{\circ} \mathrm{C}$.

\begin{tabular}{lccc}
\hline Decomposed sample & $\begin{array}{c}\text { Surface area } \\
\left(\mathrm{m}^{2} / \mathrm{g}\right)\end{array}$ & $\begin{array}{c}\text { Pore volume } \\
\left(\mathrm{cm}^{3} / \mathrm{g}\right)\end{array}$ & $\begin{array}{c}\text { Pore diameter } \\
(\mathrm{nm})\end{array}$ \\
\hline Golden snail shell & 20.495 & 0.052 & 11.319 \\
Lion snail shell & 17.308 & 0.069 & 3.753 \\
\hline
\end{tabular}

\section{CONCLUSION}

Decomposition of golden snail and lion snail was achieved at $900{ }^{\circ} \mathrm{C}$ for 3 hours to obtain calcium oxide. Calcium oxide from decomposition has diffraction similar with calcium oxide standard from JCPDS data. FTIR spectrum showed typical vibration of $\mathrm{CaO}$ and surface area analysis showed that calcium oxide from decomposition was mesoporous material.

\section{REFERENCES}

Agrawal. S., Singh. B., Sharma. Y.C. (2012). Exoskeleton of Mollusk (Pila globosa) as a Heterogeneous Catalyst for Synthesis of Biodiesel Using Used Frying Oil. Industrial \& Engineering Chemistry Research, 51, 11875-11880.

Boey. P-L., Maniam. G.P., Hamid. S.A. (2009). Biodiesel Production via Transesterification of Palm Olein Using Waste Mud Crab (Scylla serrata) Shell as a Heterogeneous Catalyst. Bioresource Technology, 100, 6362-6368.

Chakraborty. R., Banerjee. S.B.A. (2011). Application of Calcined Waste Fish (Labeo rohita) Scale as Low-cost heterogeneous Catalyst for Biodiesel Synthesis. Bioresource Technology, 102, 3610-3618.

Elkins. T.W., Roberts. S.J., Hagelin-Weaver. H.E. (2016). Effects of Alkali and Alkaline-Earth Metal Dopants on Magnesium Oxide Supported Rare-Earth Oxide Catalysts in the Oxidative Cou- pling of Methane. Applied Catalysis A: General, 528, 175-190.

Lesbani. A., Tamba. P., Mohadi. R., Riyanti.F. (2013). Preparation of Calcium Oxide from Achatina Fulica as Catalyst for Production of Biodiesel from Waste Cooking Oil. Indonesian Journal of Chemistry, 13, 176-180.

Lesbani. A., Sitompul. S.O.C., Mohadi. R., Hidayati. N. (2016). Characterization and Utilization of Calcium Oxide $(\mathrm{CaO})$ Thermally Decomposed from Fish Bones as a Catalyst in the Production of Biodiesel from Waster Cooking Oil. Makara Journal of Technology, 20, 121-126.

Nakatani. N., Takamori. H., Takeda. K., Sukugawa. H. (2009). Transesterification of Soybean Oil Using Combusted Oyster Shell Waste as a Catalyst. Bioresource Technology, 100, 15101513.

Tang. Y., Xu. J., Zhang. J., Lu. Y. (2013). Biodiesel Production from Vegetable Oil by Using Modified $\mathrm{CaO}$ as Solid Basic Catalyst. Journal of Cleaner Production, 42, 198-203.

Viriya-empikul. N., Krasae. P., Puttasawat. B., Yoosuk. B., Chollacoop. N., Faungnawakij. K. (2010). Waste Shell of Mollusk and Egg as Biodiesel Production Catalysts. Bioresource Technology, 101, 3765-3767.

Wei. Z., Xu. C., Li. B. (2009). Application of Waste Eggshell as Low-cost Solid Catalyst for Biodiesel Production. Bioresource Technology, 100, 2883-2885. 